\title{
PRECEDENTES Y EPÍGONOS DEL PERSONAJE DE FÍGARO
}

Mercedes Boixareu

UNED

Dentro del fenómeno literario del multiculturalismo, el caso del Fígaro de Beaumarchais es particularmente significativo por la rapidez con que el personaje se difunde, atravesando no sólo las fronteras del ámbito cultural francés en que se produce, sino la literatura misma, debido a su éxito en el género operístico hasta el punto que, rebasando al personaje como tal, se convierte en un periódico francés de amplia difusión, en seudónimo de un gran escritor español y en sustantivo italiano.

Fígaro, como Carmen, es uno de estos personajes-temas, o más exactamente personajes-mitos, de creación moderna que, generados en un ámbito cultural determinado -el francés-, pertenecen a un ámbito de ficción distinto - cl español- y se expanden a otras culturas, manteniendo relaciones ambiguas y complejas con el contexto cultural de producción (francés) y el contexto cultural de origen del personaje (español). Así, contrariamente a otros mitos literarios que, a pesar de su universalización, quedan vinculados a un mismo contexto de producción y de origen -por ejemplo Don Juan o el Quijote- estos otros personajes, engendrados y nacidos fuera de su tierra, están sujetos a destinos contradictorios. Así, mientras Carmen recoge y emblematiza el tópico hispánico de la mujer libre, apasionada y posesiva, que aparece en narraciones diversas y en los relatos de viajeros franceses a España desde el siglo XVII hasta el XIX, Fígaro, aunque emparentado con el personaje del "pícaro", no se corresponde en el imaginario francés con los tópicos de intolerancia y antiprogreso con los que se había emblematizado a España en el siglo XVIII'.

Y es que Fígaro pertenece a una temática mucho más amplia y compleja, la que, vinculada a la figura del criado, se remonta a la literatura grecolatina y enlaza tanto con la comedia española

1.- Sobre estas cuestiones, véase nuestro estudio M. Boixareu, R. Lcfere (2002), La Historia de España en la literatura Francesa. Una Fascinación... Madrid: Castalia. 


\section{PRECEDENTES Y EPÍGONOS DEL PERSONAJE DE FIGARO}

como con la Comedia del Arte italiana, a través de tres grandes autores franceses que son Molière, Lesage y probablemente tambićn Marivaux, aunque está muy directamente relacionado con la propia experiencia personal reivindicativa (los famosos Mémoires que relatan sus juicios), viajera y aventurera de su creador.

Trataré de esbozar los rasgos literarios más distintivos de la figura del criado y sus coláteres, el escudero o la confidente, para tratar de ver cuáles de ellos se corresponden con el Fígaro o los Fígaros de Beaumarchais, y de éstos cuáles son comunes con los precedentes aludidos. A partir de estas consideraciones será interesante observar cómo Fígaro continúa o más bien escapa a su condición de criado en los epígonos que toman su nombre.

Desde un punto de vista literario -si no desde un punto de vista sociológico- el criado se caracteriza por una falta de autonomía, o incluso de identidad ${ }^{2}$. Es un ser predeterminado que vive en función de otra persona, a la que sirve y que es la que goza de una existencia propia. En este sentido de subordinación existencial, si no de complementariedad, o mejor, de subsidiariedad funcional, este personaje se emparenta con el escudero de la literatura heroica y caballeresca, y con la confidente del teatro clásico. El interés de estos personajes "servidores" residen una posible especificidad contrapuntística que, sin menoscabo de la funcionalidad que les es propia, les confiere una identidad equivalente a la de su amo o señor (Sancho Panza frente a Don Quijote). En otras ocasiones, el interés reside en el esfuerzo que deben realizar para acceder a una existencia autónoma, sea por manipulación, emulación o anulación del personaje-amo. La manipulación es la propia de tantos personajes de comedia, y el criado, rápido y astuto, es un personaje fundamentalmente intrigante que mueve la acción. Lo encontramos en el Pseudolus de Plauto formando parte de una tradición de la época romana, heredada de la comedia griega, es el Daos (Davus) de Menandro y en Francia, todavía en el siglo XVIII, "dave" es el "valet de comédie". Son los Scapin y Sganarelle de Les Fourberies de Scapin y del Don Juan de Molière. En este autor los criados ayudan a los enamorados, normalmente los hijos jóvenes, a burlar los designios de sus padres, burgueses ridículos devotos, avaros o enfermos imaginarios.

La emulación del personaje-amo se da cuando el criado pretende dotarse de una existencia propia, por los caminos que la sociedad le ofrece en un momento determinado, a fin de escapar a su condición y llegar a ser como su amo. Es el criado arribista de Le paysan parvenu (Marivaux), el pícaro establecido que hace pensar en Gil Blas y en tantos otros, empezando por el primigenio Lázaro de Tormes en su irónico final, héroes o más bien antihéroes que traspasan los distintos estratos de una sociedad cada vez más porosa, que les permite acceder a un status social de independencia, a partir del cual afirman su propia identidad. Es el tema de la ascensión social, tan importante en cl siglo XVIII francés.

Al criado arribista le sucede, o se le opone, el criado subversivo: éste es el que utiliza sus astucias y su capacidad de intriga para hacer frente al $\mathrm{amo}^{3}$, a fin de buscar su propia felicidad y afirmar así su propia identidad.

La anulación del poder del amo aristócrata pasa por el cuestionamiento de unos derechos aristocráticos que invaden el espacio de la intimidad personal y violan los cuerpos y voluntades de quienes dependen de ellos. En este sentido, cs de obligada referencia la relación temática que existe en el teatro español entre el "gracioso" de la comedia y el padre, marido o prometido, vengador de la tragedia, a través de la figura del villano, estudiada por Noël Salomon"; el villano es criado

2.- Efectivamente, como recuerda Van Tieghem (1969), el personaje del criado asume un empleo, no un papel, en Technique du théatre, París: PUF, p. 22.

3.- Véase el interesante artículo de Georges Zaragoza (1998), "Le barbier de Séville ou comment faire la barbe à tout le monde" en Le triomphe du valet de comédie. Plaute. Goldoni. Beaumarchais. Hofmannsthal. Études recueillies par Daniel Mortier, París: Champion, p. 99.

4.- Salomon, N. (1985), El villano en el Siglo de Oro, Madrid: Castalia. 


\section{MERCEDES BOIXAREU}

bobo, a veces gracioso, burlón otras, o bien es villano vengador de los abusos aristocráticos, los Pedro Crespo, Peribáñez, pero sobre todo Fuenteovejuna, "la foule obscure" de donde, en sus propias palabras, procede Fígaro (Las bodas, Acto V, escena III).

El Fígaro de Beaumarchais pertenece a esta categoría, aunque en la gestación del personaje se pueden distinguir dos momentos que corresponden a las dos obras, Le barbier de Séville (1775) (cn adelante El barbero) y Le mariage de Figaro (en adelante Las bodas), estrenada en 1784 por no citar La mère coupable (1792), en que reaparece un Fígaro más sensible, con menos fuerza e interés. Como indica el título, en la primera Fígaro no es criado, sino barbero, y el personaje, que no es, pero ha sido criado, se explica a sí mismo a partir de su experiencia diversa que lo emparenta con el pícaro español. Fígaro aparece en escena apelando a la bebida y a la pereza: «Le vin et la paresse/ se disputent mon coeur...» (Acto I, escena II). Fígaro, como otro Gil Blas, alude a sus distintos oficios: empleado en el Ministerio para el que le recomendó Almaviva, "mancebo de botica" que «vendía a los campesinos las medicinas que preparaba para los caballos» y finalmente autor de poemas, charadas y madrigales que -como en el caso de Beaumarchais- le llevan a la desgracia.

Ya en esta escena de presentación del Acto I, Fígaro aparece vinculado al criado que fue y al pícaro que se caracteriza por sus astucias. La futura confrontación amo-criado que se dará en Las bodas se anuncia aquí cuando el antiguo criado sacude la imagen negativa que guarda $\mathrm{cl}$ amo:

LE COMTE.- Tu ne dis pas tout. Je me souviens qu'à mon service tu étais un assez simple mauvais sujet.

FIGARO.- Eh, mon Dieu! monseigneur, c'est qu'on veut que le pauvre soit sans défaut.

LE COMTE.- Paresseux, dérangé...

FIGARO.- Aux vertus qu'on exige dans un domestique, Votre Fxcellence connait-elle beaucoup de maîtres qui fussent dignes d'être valets?"' (Acto I, escena II). ${ }^{5}$

A partir de la fundamentación moral, la réplica subvierte ya, en tono jocoso, pero profundamente sarcástico, el valor de las condiciones sociales.

En El barbero, Fígaro, a causa de la facilidad que el nuevo oficio de barbero le procura para introducirse en las casas, vuelve a "servir" al conde Almaviva, deshaciendo el matrimonio de Rosina con su tutor Bartolo y favoreciendo que sea Almaviva quien se case con ella.

A pesar de las réplicas subversivas, a pesar de ser Fígaro el agente de la intriga, el personaje funciona como cómplice y "servidor" del conde que es a quien se le facilita la consecución de unos objetivos. En esta obra, Fígaro, a pesar de su protagonismo actancial, no arranca al criado de su subsidiariedad funcional, en la que todavía está anclado a pesar de sus audaces predecesores los Crispin y los Frontin. Su identidad se afirma por la superioridad de su saber-hacer, su desenvoltura y sus astucias.

Entre El barbero y Las bodas, la Lettre modérée sur la chute et la critique du Barbier de Séville (1775), Beaumarchais, además de comentar las posibles razones que motivaron las cábalas contra la primera, el autor imagina para su Fígaro, personaje sin orígenes, una genealogía que se revelará como desenlace en la escena XVI del Acto III de Las bodas. En el siglo XVIII abunda el personaje del huérfano, o de la huérfana, tal la Marianne de Marivaux que tiene que afirmar su existencia, y su identidad, a partir de sus actos. Pero en el huérfano digno y "noble" existe siempre la sospecha de que, sin saberlo, puede ser hijo de unos padres aristócratas "nobles", lo que explica su natural bondad y sus elevados sentimientos. Beaumarchais hace de Fígaro, no un huérfano sino un hijo bastardo

5.- Citamos los textos de las obras según la edición, Beaumarchais, P. A. Caron de (1980), Théâtre; texte établi, introduction, chronologie, bibliographie, notices, notes et choix de variantes par Jean-Pierre de Beaumarchais, París: Garnier. 


\section{PRECEDENTES Y EPÍGONOS DEL PERSONAJE DE FIGARO}

del viejo Bartolo, el mismo a quien le impidió casarse con Rosina, y de Marcelina, personaje que refuerza en su próxima obra La mère coupable; con estos orígenes indignos y mediocres, Fígaro tiene que seguir labrándose una identidad que dependerá de su capacidad de acción, pero también de la defensa de su dignidad como persona y como marido. Esta dignidad está puesta en tela de juicio desde la primera escena del Acto I de Las bodas cuando Susana, su novia, criada de la condesa, como él lo es de nuevo del conde, le descubre la voluntad de este último de seducirla. La alusión al abolido derecho de pernada supone el recuerdo del poder de la aristocracia que extendía sus derechos del ámbito social y público al ámbito privado y más íntimo. Almaviva desea seguir siendo el actor beneficiario de aquellos derechos abolidos, y en lo dramático, de la intriga.

Esta vez, no obstante, los deseos del señor contrarían los deseos (y derechos) del criado, que no consentirá en ello, y esta vez la acción de Fígaro debe redundar en beneficio propio. El criado reivindica su derecho conyugal, su felicidad, su dignidad, y para ello se convierte en el agente de una intriga de cuyo desenlace ya no será actor-espectador, sino actor-autor. Fígaro no va a "servir" a su amo, no pretende emularle, sino que va a "anularle", denunciando la irrelevancia de lo que define al noble: una identidad basada en la genealogía: "Qu'avez-vous fait pour tant de biens? Vous vous êtes donné la peine de naître et rien de plus: du reste, homme assez ordinaire» (Acto V, escena III). Lo único que tiene que hacer el personaje noble-amo es nacer, y su condición le da sus derechos. Fígaro, que en El Barbero ya ironizaba sobre la falta de imperativos morales de una aristocracia, reclama ahora cl derecho a la identidad a través de la acción: «Tandis que moi, morbleu, perdu dans la foule obscure, il m'a fallu déployer plus de science et de calculs pour subsister seulement, qu'on n'en a mis depuis cent ans à gouverner toutes les Espagnes; et vous voulez jouter!... » (Acto V, escena III).

El acto, la experiencia que es esfuerzo de El barbero a Las bodas, define la existencia, y con ello se configura la identidad de un personaje, que ya no es ni subsidiario, ni complementario, sino que existe por sí mismo Fígaro, en su oscura etimología (ya sea "pícaro" o "fils-Caron", ya sea un nombre basado en un topónimo español del norte de Barcelona - El Figaro-que, como otro Hernani, captaría la atención del viajero Beaumarchais), constituye su propio mito, a partir de su personaje astuto y burlón, pero sobre todo a partir de su palabra y de su acción subversiva: en términos greimasianos Fígaro pasa de adyuvante del conde a ser su oponente, y el dúo del barbero se convierte en duelo .

Esta doble componente de la subversión por la comicidad, no por la tragedia, le asegura un doble futuro, el de la ópera y el de la denuncia (viajera y periodística).

Por otra parte Fígaro se constituye en símbolo de subversión a causa del sistema cultural de producción del momento, en vísperas de la Revolución Francesa. El barbero había tenido fuertes dificultades para hacerse representar a causa de su desenfado y jocosidad desafiante, pero el horizonte de cxpectativas en el que se dan Las bodas es mucho más tenso y agresivo; cl público está mucho más pendiente del nuevo escándalo Beaumarchais, especialmente debido a que el rey y la censura se resisten a su representación 6 .

Su éxito -entre Abril y Septiembre sesenta y siete representaciones-, su trascendencia política, además de las cualidades dramáticas propias de ambas obras -ligereza, comicidad, cambios de situación-, atraerán a los compositores del género operístico, primero a Paisiello, luego a Mozart, más tarde a Rossini.

6.- El 27 de Abril 1784, el Théâtre-Français abría las taquillas a las 4 de la tarde y desde las 6 de la mañana, medio París -el París aristócrata sobre todo- hacía cola. 


\section{MERCEDES BOIXAREU}

Paisiello estrena su Barbero de Sevilla en la corte de Catalina la Grande, en S. Petersburgo y desde allí en 1782, se difunde a toda Europa. En Viena, en 1783 el éxito fue clamoroso.

Las bodas de Fígaro de Mozart son como una continuación en la escena vienesa de la obra de Paisiello. No obstante, como Beaumarchais, la obra tiene que debatirse con las reticencias del Emperador y el libreto tiene que purgar sus osadías ideológicas. Da Ponte lo cuenta en sus Memorias:

En conversación conmigo, un día... (Mozart) me preguntó si yo podría hacer fácilmente una ópera de una comedia de Beaumarchais: Le Mariage de Figaro. Me gustó mucho la sugerencia y le prometí escribirla. Pero había una dificultad muy grande que superar. Unos días antes el emperador había prohibido a la compañía del teatro alemán interpretar la comedia, que según él era demasiado licenciosa para un público respetable?

Da Ponte explica cómo deciden, el músico y él trabajar en secreto, esperando la oportunidad favorable para hacer una propuesta al Emperador. Transcribe la conversación con éste, en el que le dice haber omitido algunas escenas y cortado otras (Acto III, Escena V, confrontación de Fígaro y el conde; y el monólogo del Acto V, escena III) hasta conseguir el permiso del monarca. Podemos afirmar que la obra de Mozart, más que la de Beaumarchais, difunde al personaje del criado que encarna las reivindicaciones del pueblo, con el que la Revolución se enardece y se sentirá identificada.

En las versiones operísticas, y a pesar de las transformaciones de los distintos libretos, Fígaro sigue siendo el barbero de Sevilla y el criado del conde Almaviva creado por Beaumarchais.

No obstante en Francia, de manera inmediata, el personaje va a independizarse y a continuar una vida propia, liberándose de su condición de criado, pero guardando su ("verbe") palabra denunciadora de injusticias, progresiva y subversiva. O cuanto menos esto pretendía su primer continuador Jean-Marie-Jerôme Fleuriot de Langle, quien ya en 1784, el mismo año del estreno de Las bodas, aprovechándose de la fama del personaje y dentro de la tradición de la literatura de viajes, hace viajar a este hijo de las luces francesas -que no ilustrado español-por su propio país de origen, pero con la mirada más convencional y estereotipada que puede darse, sobre todo teniendo en cuenta que lo más probable es que este autor del Voyage de Figaro en Espagne, nunca hubiera estado en nuestro país La visión de España es una sucesión de lugares comunes: incomodidades viajeras, suciedad de las ciudades, indigencia de las posadas y albergues, hipocresía social, Inquisición, abusos del clero, inmoralidades... El cuadro es tan deplorable que al año siguiente aparece la Dénonciation au public, Du voyage d'un soi-disant Figaro en Espagne. Par le véritable Figaro, texto publicado en Londres y París: Fournier, 1785. El autor de tal denuncia se llama Pedro Pablo de Abarca y Bolea, conde de Aranda ${ }^{8}$, quien, recordando la nacionalidad de Fígaro, se autoatribuye la veracidad del personaje y el "falso Fígaro" o el "llamado Fígaro" ("le soi-disant Figaro") queda desautorizado y con él la autenticidad de su testimonio pseudoviajero: «Quoi qu'il en soi le prétendu voyageur ayant jugé à propos de prendre le nom de Figaro, celui-ci, (el conde de Aranda), en bon patriote, a cru devoir réclamer contre cette usurpation et denoncer l'ouvrage au public». La reclamación va de la Corte española a la Corte francesa, y el libro llega a prohibirse a petición de Carlos III.

El Fígaro viajero, testigo convencional y crítico, se continúa con poca fortuna en otra obra del mismo Fleuriot de Langle, el Voyage de Figaro à Ténérife, de 1786, otro viaje no experimentado pues el autor calca su propio texto en otra obra titulada Tableau pittoresque de la Suisse.

7.- Citada en H. C. Robbins Landon (1990), Mozart. Los años dorados 1781-1791, Barcelona, Destino.

8.- Véase Benimelli, José Antonio (1972), El conde de Aranda y su defensa de España, Zaragoza, Universidad de Zaragoza. 


\section{PRECEDENTES Y EPÍGONOS DEL PERSONAJE DE FIGARO}

Este Fígaro viajero llega hasta nuestros días y en su homónimo, el Fígaro magazine, aparece en 1994 Le voyage de noces de Figaro, de Félicien Marceau, que se publica al año siguiente en Librio. Se trata de un texto de escaso interés en el que Fígaro, acompañado esta vez por su esposa Susana, realiza un viaje por Europa (desde sus apartamentos de Madrid -no de Sevilla- y a través de Marsella recorre Ginebra, Venecia, Roma, Nápoles, Trieste, Zagreb, Vicna, Bcrlín y Hamburgo).

Ya en época de la Restauración francesa aparece el primer Figaro, periódico satírico, antirromántico, que, como el personaje que le da su nombre, hace gala de ingenio, malicia y se rige por un espíritu de denuncia que le cuesta varios juicios que acaban terminando con él.

El 2 de Abril de 1854 aparece otro Figaro, fundado por M. de Villemessant, periódico también de escándalos, burlas y sarcasmos. En 1856, y tras otros varios juicios por difamación, la censura intenta de nuevo su supresión.

A partir de 1866 la periodicidad se hace diaria y a finales de siglo el subversivo y escandaloso Figaro entra en los esquemas que le asegurarán su supervivencia hasta convertirse en el periódico moderado que conocemos hoy.

Finalmente recordamos que la verdad dolorosa y la denuncia periodística de la España decimonónica, llevaron a aquel hijo de afrancesados, Mariano José de Larra, a firmar con el pseudónimo de Fígaro sus artículos periodísticos en los que ironiza sobre los defectos ancestrales y consuetudinarios del país al que pertenece y en el que vive.

Así pues el Fígaro de Beaumarchais heredero de los esclavos-criados de la comedia clásica, del pícaro novelesco, del gracioso de la comedia española, así como de distintos personajes de la Comedia del Arte, crea un personaje muy propio que utiliza los recursos de sus predecesores, la astucia y la sátira social no sólo para ridiculizar en clave de comedia, después de ópera, a la nobleza decadente, sino sobre todo para dignificar y dar carta de identidad al hombre-criado, el que proviene de las sombras de inexistencia del hombre-pueblo. Este recorrido abarca una amplia temática que se continúa, de forma diversa, hasta nuestros días con Hofmannsthal, Brecht, Beckett, sin olvidar en el nuevo arte cinematográfico un clásico, El sirviente de J. Losey. 